\title{
Characterization and Determination of Major Bioactive Acids in Camel Urine Using Gas Chromatography Mass- spectrometry
}

\author{
A. KHEDR* AND F. KHORSHID ${ }^{1}$ \\ Pharmaceutical Chemistry Department, Faculty of Pharmacy, ${ }^{1}$ Biology Department, Faculty of Science, King \\ Abdulaziz University, Jeddah 21589, Saudi Arabia
}

Khedr: Major Bioactive Acids in Camel Urine Using GC/MS

\begin{abstract}
The major acidic and phenolic biogenic materials in adult-camel urine were characterized using gas chromatography-mass spectrometry. The adult-camel urine sample was treated with glucuronidase/ arylsulfatase enzyme followed by extraction on Sep-Pak ${ }^{\circledR} \mathrm{C8}$ column. The water soluble compounds, including urea and creatinine, were washed out using water containing $0.4 \%$ trifluoroacetic acid. Ethyl acetate:diethylether, 1:1 v/v, was used as extraction solvent. The extraction residue was reprivatized with $N$-methyl- $N$-(trimethylsilyl) trifluoroacetamide followed by gas chromatography-mass spectrometry analysis. The average concentrations of, phenol, p-cresol, salicylic acid, cinnamic acid, azelaic acid and benzoic acid were 4.0, 107.2, $42.7,3.2,68.6$ and $490.6 \mathrm{mg} / 100 \mathrm{ml}$, respectively. The calibration range of each of these compounds was spanning the range of 1.0 to $50 \mathrm{ng} / \mu \mathrm{l}$. The extraction recovery of all studied compounds was $100 \pm 0.8 \%$. A standard solution mixture containing the major acidic and phenolic compounds was prepared to contain the same corresponding concentration in adult-camel urine. Both, adult-camel urine and prepared standard mixture were active against Bacillus subtilis, Staphylococcus aureus, Escherichia coli, Pseudomonas aeruginosa, Aspergillus flavus (fungus) and Candida albicans (fungus) after $72 \mathrm{~h}$ of incubation.
\end{abstract}

Key words: Camel urine, antimicrobial, gas chromatography-mass spectrometry, azelaic acid, p-cresol, cinnamic acid

Traditionally, adult camel urine (CUR) has been claimed to exhibit anticancer, antimicrobial and antifungal effect upon administration orally or topically. To date, there is no evidence that these effects are due to the urine of these camel. The objective of this work is to find out the bioactive material in relation to any of the claimed activities. The chemical composition of camel urine has been reported to contain organic nitrogen, ammonia, urea, creatinine, creatine, hippuric acid and chloride ${ }^{[1]}$. Recently, more details about camel urine composition using liquid chromatography-mass spectrometry have been reported ${ }^{[2]}$. This information showed many metabolites in camel urine. Benzoic acid (BEN), urea, creatinine, phenylacetate, citric acid and hippuric acid have been reported as the major constituents in camel urine. The concentration of these materials was matched with the amounts found in different camels, elephant and rat urine. The amount of benzoate salt was greatest in camel urine. To date, the fully characterized chemical composition of camel urine, not yet reported. Al-Abdalall ${ }^{[3]}$, proved that camel urine at low concentrations had no significant

*Address for correspondence

E-mail: akhedr@kau.edu.sa

September-October 2016 inhibitory effect on fungal growth, while inhibition can be obviously recorded after using high concentrations. Moreover, camel urine has been proved to have a potent antiplatelet activity against adenosine diphosphateinduced and arachidonic acid induced platelet aggregation; neither human nor bovine urine exhibited such properties ${ }^{[4]}$.

Our research investigated the chemical nature and composition of camel urine to know which substance(s) gave antimicrobial and antifungal activities. This leads us to characterize the most suspicious materials in CUR that could have antimicrobial activity. Herein, described a sequential procedures including, enzymatic hydrolysis of glucuronides/sulfate conjugates, solidphase extraction, followed by derivatization. The

This is an open access article distributed under terms of the Creative Commons Attribution-NonCommercial-ShareAlike 3.0 License, which allows others to remix, tweak, and build upon the work non-commercially, as long as the author is credited and the new creations are licensed under the identical terms.

Accepted 25 October 2016

Revised 18 October 2016

Received 22 June 2015

Indian J Pharm Sci 2016;78(5):680-687 
derivatized sample extract was analyzed by gas chromatography-mass spectrometry (GC-MS) to characterize and to measure the major bioactive antimicrobial materials.

\section{MATERIALS AND METHODS}

Adult camel urine (1-5 y old) samples were collected, freely voided, at the morning, just before sunrise, in clean containers. Adult human urine was collected from healthy volunteers, $n=6$. Sample volume and $\mathrm{pH}$ were measured and immediately treated for the analysis or maintained at $-80^{\circ}$ in labeled separate containers.

Sodium benzoate (BEN), purity $>99 \%$, p-cresol (CRE), phenol (PHE), azelaic acid (AZE), cinnamic acid (CIN) and salicylic acid (SAL), were purchased from Sigma-Aldrich (Fluka, Steinheim, Germany). $\beta$-glucuronidase/arylsulfatase (Helix pomatia, type HP- $2 \geq 500,000$ units $/ \mathrm{ml}$, Sigma units $\beta$-glucuronidase and $\leq 37.5$ units sulfatase activity) and $N$-methyl $-N$ trimethylsilyl-trifluoroacetamide (MSTFA) 99.8\% w/v, were purchased from Sigma-Aldrich (St. Louis, MO, USA). 3-hydroxymethyl-propyphenazone (3-OH-MP, m. wt. 246) was prepared in our laboratory by boiling, $1 \mathrm{~g}$ of 3-bromomethyl-propyphenazone in $50 \mathrm{ml}$ water for $30 \mathrm{~min}^{[5]}$. The obtained crystals were washed with $0.1 \%$ sodium carbonate followed by water, filtered and dried over sodium hydroxide pellets in desiccators. The purity of 3-OHMP was verified by GC-MS, melting point and LC-MS. A concentration of $40 \mathrm{ng} / \mu \mathrm{l}$ of 3-OHMP was prepared in acetone and used as an internal standard. The tested micro-organisms, bacteria and yeast strains were obtained from the Micro-Analytical Center, Faculty of Science, Cairo University, Egypt. Gram-positive bacterial strains: Staphylococcus aureus (ATCC 12600) and Bacillus subtilis (ATCC 6051) and Gram-negative bacterial strains: Escherichia coli (ATCC 11775), Pseudomonas aeruginosa (ATCC 10145), yeast: Candida albicans (ATCC26555) and fungi: Aspergillus flavus (ATCC 204304) were used for antibacterial and antifungal screening. Solid-phase extraction (SPE) columns, SepPak $^{\circledR}$ Vac 1cc (100 mg) C8 cartridge were purchased from Waters, Ireland. Extraction manifold, $16 \times 75 \mathrm{~mm}$ tubes, with Buchi vacuum pump V-700 and the screwcapped (PTFE/silicon) $1 \mathrm{ml}$ total recovery autosampler vials $(12 \times 32 \mathrm{~mm})$ were purchased from Waters (Waters, Milford, MA, USA). Screw-capped borosilicon minireaction vials (v-shaped, with TFE liners, Alltech, $\mathrm{GmbH}$, Unterhaching, Germany) were used for derivatization at elevated temperature. Solvents and all other materials were of analytical grade.

\section{Instrument and conditions:}

GC-MS: Clarus 500 GC-MS (Perkin Elmer,Shelton, CT, USA) was utilized throughout the experiments. The software controller/integrator was TurboMass version 5.4.2.1617. An Elite-1 GC capillary column, Crossbond $^{\circledR} 100 \%$ dimethyl polysiloxane $(30 \mathrm{~m} \times 0.25$ $\mathrm{mm}$ ID $\times 0.25 \mu \mathrm{m}$ df, Perkin Elmer) was used. The carrier gas was helium (purity $99.9999 \%$ ) and flow rate was $0.9 \mathrm{ml} / \mathrm{min}$. Source (EI+): source temperature was $270^{\circ}$. GC line temperature was $210^{\circ}$. Electron energy was $70 \mathrm{eV}$, and trap-emission was $100 \mathrm{~V}$. The oven was programmed as follows: initial temperature was $70^{\circ}$ (hold $2 \mathrm{~min}$ ) to $150^{\circ}$ (rate $10^{\circ} / \mathrm{min}$, hold $5.0 \mathrm{~min}$ ), followed by an increase to $220^{\circ}$ (rate $10.0^{\circ} / \mathrm{min}$, hold $5 \mathrm{~min}$ ), then increased to $280^{\circ}$ (rate $20^{\circ} / \mathrm{min}$, hold 2.0 $\mathrm{min})$. The injector temperature was $260^{\circ}$. The injection volume was $1.0 \mu \mathrm{l}$ and the split ratio was $40: 1$. The run time was $32 \mathrm{~min}$. Samples were acquired by applying a total MS scan from 40 to $350 \mathrm{~m} / \mathrm{z}(500 \mathrm{scan} / \mathrm{s})$.

\section{Enzymatic hydrolysis:}

$\beta$-Glucuronidase arylsulphatase enzyme was used to hydrolyze the glucuronides or suphate conjugated compounds in the urine. In $250 \mathrm{ml}$ round flask, a volume of $30 \mathrm{ml}$ camel urine was mixed with $1 \mathrm{ml}$ of $2 \mathrm{M}$ sodium acetate and adjusted to $\mathrm{pH} 5.5$ with acetic acid or $1 \mathrm{M}$ sodium hydroxide solution. This solution was mixed with $200 \mu \mathrm{l} \beta$-glucuronidase/ arylsulphatase. The reaction mixture was left for $24 \mathrm{~h}$ at $42^{\circ}$ in thermostatically controlled water bath. The reaction was stopped by addition of $100 \mu \mathrm{l}$ of $\mathrm{CH}_{2} \mathrm{Cl}_{2}$ or extracted immediately using SPE columns.

\section{Extraction of camel urine:}

The Sep-Pak ${ }^{\circledR}$ Vac $1 \mathrm{cc}(100 \mathrm{mg}) \mathrm{C} 8,100 \mu$, extraction cartridge was fitted to a vacuum manifold and condition with $2 \mathrm{ml}$ methanol followed by $2 \mathrm{ml}$ water containing $0.4 \%$ trifluoroacetic acid (v/v). The column end was closed and a volume of $100 \mu \mathrm{l} 0.4 \%$ TFA and $100 \mu \mathrm{l}$ CUR sample solution was added. The sample was allowed to flow through the column at a flow rate of 10 drops/min. The sample was cleaned-up with $1 \mathrm{ml} \mathrm{0.4 \%}$ TFA solution, followed by $1 \mathrm{ml}$ water and left under vacuum for $5 \mathrm{~min}$ to expel the adsorbed water. The column was fitted to another port with a clean test tube containing $100 \mu \mathrm{l}$ of $0.6 \% \mathrm{v} / \mathrm{v}$, triethylamine in acetone and $100 \mu \mathrm{l}$ of 3-OHMP, $40 \mathrm{ng} / \mu \mathrm{l}$. Two milliliter of the extraction solvent (ethylacetate:diethylether; $1: 1, \mathrm{v} / \mathrm{v}$ ) was added and allowed to flow through the column at slow flow rate. The eluent was then dried under a 
gentle stream of nitrogen gas at room temperature. The residue was reconstituted in $100 \mu$ ethylacetate: diethylether; $1: 1 \mathrm{v} / \mathrm{v}$, transferred to total recovery vial and dried with nitrogen gas. Trimethylamine solution was used to suppress the volatilization of phenolic compounds during the step of drying with nitrogen gas.

\section{Reaction with MSTFA:}

The hydroxyl, carboxylic, and amino compounds were trimethylsilylated using MSTFA. The vial containing the extract residue was mixed with $50 \mu \mathrm{l}$ of MSTFA, closed cap and heated at $80^{\circ}$ for $10 \mathrm{~min}$, using block heater (designed for half insertion of vials). The reaction mixture was cooled to room temperature, and a volume of $1 \mu 1$ was injected for GC-MS analysis.

\section{Preparation of calibration mixture:}

The calibration mixture was prepared by dissolving $100 \mathrm{mg}$ of each; phenol (PHE), p-cresol (CRE), benzoic acid (BEN), salicylic acid (SAL), cinnamic acid (CIN) and azelaic acid (AZE), with the aid of sonication, in $100 \mathrm{ml}$ water containing $100 \mathrm{mg}$ of $\mathrm{KOH}, 100 \mathrm{mg}$ glycine and $100 \mathrm{mg}$ glycerol. A volume of $0.5 \mathrm{ml}$ from this solution was diluted to $100 \mathrm{ml}$ with water to obtain a concentration of $50 \mathrm{ng} / \mu \mathrm{l}$, of each compounds. A serial dilution was prepared spanning the range of 1 to $50 \mathrm{ng} / \mu 1$ of each compound. A volume of $100 \mu \mathrm{l}$, from each concentration level, was extracted using Sep-Pak ${ }^{\circledR}$ Vac $1 \mathrm{cc}(100 \mathrm{mg})$ C8, derivatized with MSTFA, and analyzed by GC-MS. The calibration curves were constructed by plotting the peak area ratio of corresponding compound to 3-OHMP versus concentration as $n g / \mu l$. Potassium hydroxide was used to form less volatile and soluble salts. Glycine and glycerol were also added as solvent matrix.

\section{Preparation of antimicrobial mix:}

The antimicrobial mix was prepared to contain same average amount of characterized compounds that measured in CUR after enzymatic treatment. A weight of 40, 1072, 4906, 427, 32, $686 \mathrm{mg}$ of phenol, p-cresol, benzoic acid, salicylic acid, cinnamic acid and azelaic acid, respectively, was prepared in $100 \mathrm{ml}$ volumetric flask. This powder mixture was mixed with $17 \mathrm{mg}$ $\mathrm{KOH}$ (equimolar amount), $80 \mathrm{ml}$ water and sonicated for about $10 \mathrm{~min}$. The $\mathrm{pH}$ was adjusted to 7.9 using 0.5 $\mathrm{M} \mathrm{KOH}$ or $1 \mathrm{M}$ phosphoric acid and the final volume was adjusted to $100 \mathrm{ml}$ with water. A volume of 10 $\mathrm{ml}$ of this solution was diluted with water, to $100 \mathrm{ml}$, filtered through a sterile $0.22 \mu$ nylon membrane and tested for antimicrobial activity.

\section{Testing of antimicrobial activity:}

Three types of samples were tested for antimicrobial activity. Samples were include, fresh camel urine, enzymatic hydrolyzed CUR sample and prepared standard solution mixture containing same concentrations of the claimed bioactive materials found in CUR. Mueller-Hinton agar was used as the culture medium for bacteria, while Czapek's Dox agar (sucrose-nitrate agar) was used for yeasts and fungi. Blank paper disks (Schleicher and Schuell) with a diameter of $8.0 \mathrm{~mm}$, were impregnated with the tested compounds. Standard discs of ampicillin and amphotericin B served as positive controls for the antimicrobial activity and filter discs impregnated with dimethyl sulfoxide (DMSO) were used as a negative control. The modified Knirby-Bauer disc diffusion method was used in antimicrobial testing ${ }^{[6]}$. Briefly, $100 \mu 1$ of the test bacteria/fungi were grown in $10 \mathrm{ml}$ of fresh media until they reached a count of, approximately, $108 \mathrm{cell} / \mathrm{ml}$ for bacteria or $105 \mathrm{cell} / \mathrm{ml}$ for fungi. About $100 \mu \mathrm{l}$ of microbial suspension was spread onto agar plates corresponding to the broth in which they were maintained. Paper disks impregnated with $10 \mu \mathrm{l}$ of the tested compounds were added. Samples were incubated at $35-37^{\circ}$ for $72 \mathrm{~h}$ and yeast incubated at $30^{\circ}$ for $72 \mathrm{~h}$ and the diameters of the inhibition zones were measured in millimeters.

\section{RESULTS AND DISCUSSION}

The $\mathrm{pH}$ of fresh camel urine was ranged from 8.2 to 9.2. This basic $\mathrm{pH}$ might be due to high concentration of potassium salts ${ }^{[7]}$. Amazingly, it was very difficult to filter the fresh camel urine through 0.22 or 0.45 $\mu$ nylon filters. In addition, camel urine was found not miscible with acetonitrile, even after shaking or sonication. The liquid-liquid extraction gave low and fluctuated percentage recoveries of targeted materials. The glucuronides metabolites were enzymatically hydrolyzed before the extraction. The reported major polar compounds were identified by liquid chromatography-mass spectrometry (LC-MS) and GC-MS ${ }^{[2]}$. The confirmed major constituents in nonhydrolyzed samples were include: hippuric acid, creatinine, urea, phenaceturic acid and benzoic acid. These substances needs large amount of MSTFA and showed intense GC-MS peaks. The use of $2 \mathrm{ml}$ $0.4 \%$ trifluoroacetic acid in water, as clean-up solvent, was essential to remove this major polar unwanted compounds and to ovoid co-elution/overlap with the targeted substances. 
The enzymatic hydrolyzed CUR was extracted on Sep-Pak C8 column, washed with $0.4 \%$ TFA in water, followed by water and the eluent was derivatized with MSTFA. Fig. 1 showed the GC-MS of MSTFA derivatized CUR extract. The EI-MS spectra of investigated peaks showed most reported compounds.
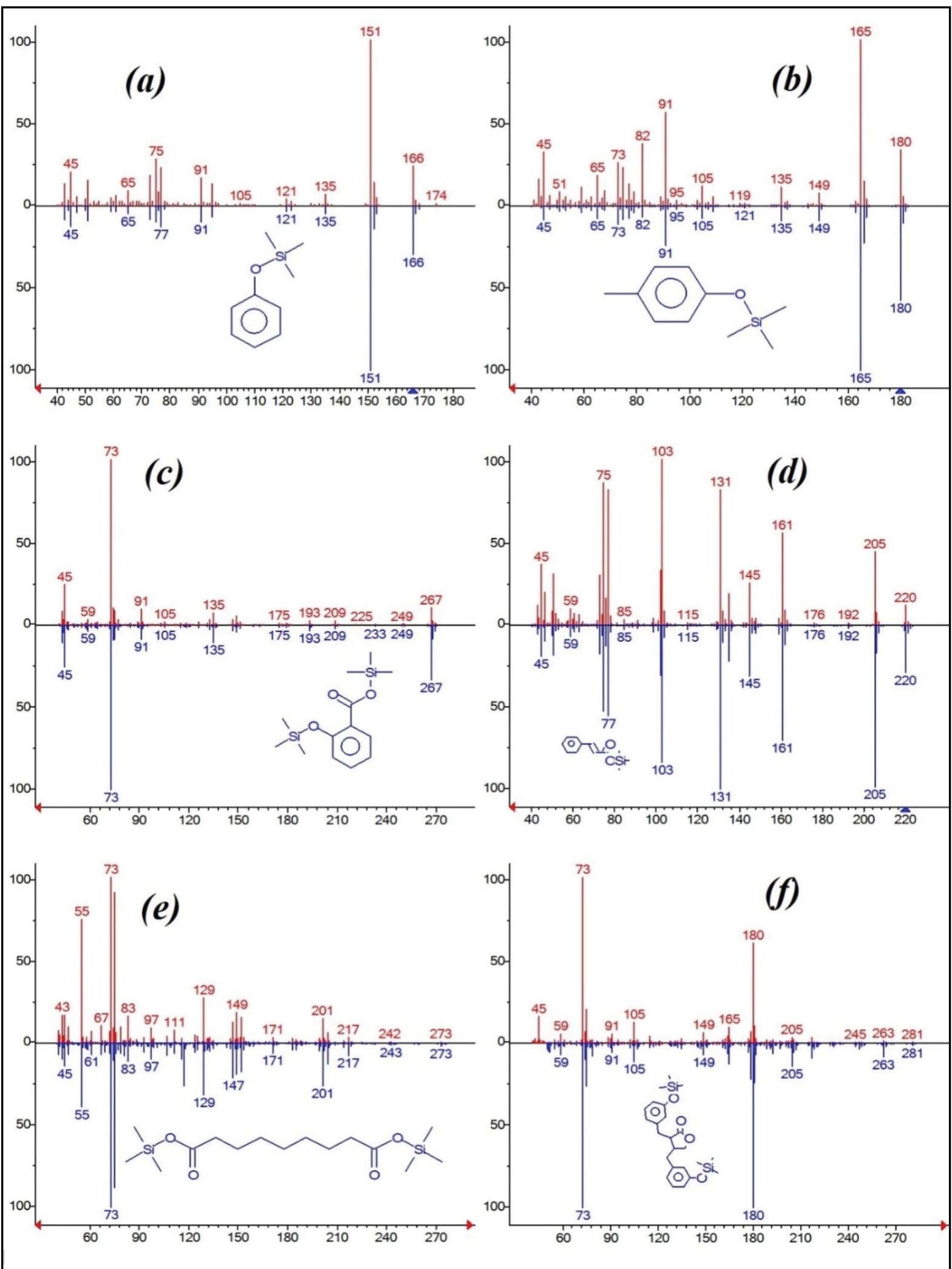

Fig. 1: EI-MS spectra of compounds found in the extract of enzymatic hydrolyzed CUR.

EI-MS spectra of characterized compounds found in the extract of enzymatic hydrolyzed CUR, as TMS derivative, including; phenol (a), p-cresol (b), salicylic acid (c), cinnamic acid (d), azelaic acid (e) and enterolactone (f). (Upright MS, compound in sample; inverted MS, search result of NIST 2008 database). 
Moreover, the GC-MS analysis showed additional bioactive compounds which are not mentioned in any previous literature. These compounds were include, phenol, p-cresol, salicylic acid, cinnamic acid, azelaic acid and enterolactone. P-cresol was the predominant phenolic compound, as per GC-MS. Other minor GCMS peaks were characterized by NIST2008, after enzymatic hydrolysis, and ignored from the assay. Those compounds were identified as TMS-derivative of; resorcinol, 3-hydroxy-benzoic acid, benzene propionic acid, 3-phenyl-3-hydroxypropanoic acid, 4-methylcatechol and $\alpha$-(methoxyimino) benzenepropanoic acid (fig. 2).

The simulated camel urine was prepared to contain the most interesting compounds that known to exhibit therapeutic activity and marketed as drugs. A topical formulation contain $6 \%$ benzoic acid and 3\% salicylic acid has been described an effective treatment of Tinea Unguium $^{[8]}$. Azelaic acid was one of the major new constituents found in camel urine. Skinoren ${ }^{\circledR}$ cream is Italian pharmaceutical topical formulation found in the market. This formulation contains $20 \% \mathrm{w} / \mathrm{w}$, of azelaic acid and prescribed for the treatment of acne and hyperpigmentation in skin. Azelaic acid has been proved as an effective treatment of Papulopustular rosacea and hyperpigmentation in $\operatorname{skin}^{[9]}$.

The GC-MS analytical method was optimized using standard substances. Many extraction solvents were tried including, methanol, dichloromethane, chloroform, ether and n-hexane. Methanol extract showed many interfering extracted substances including the residual amounts of polar compounds. Chloroform and dichloromethane showed a very low $\%$ recover of the targeted compounds $(<72 \%)$. The optimal extraction solvent was a mixture of ethylacetate and diethylether $(1: 1 \mathrm{v} / \mathrm{v})$. This solvent mix showed optimal extraction of targeted compounds with minimal co-eluted interfering polar components. The average percentage recovery,

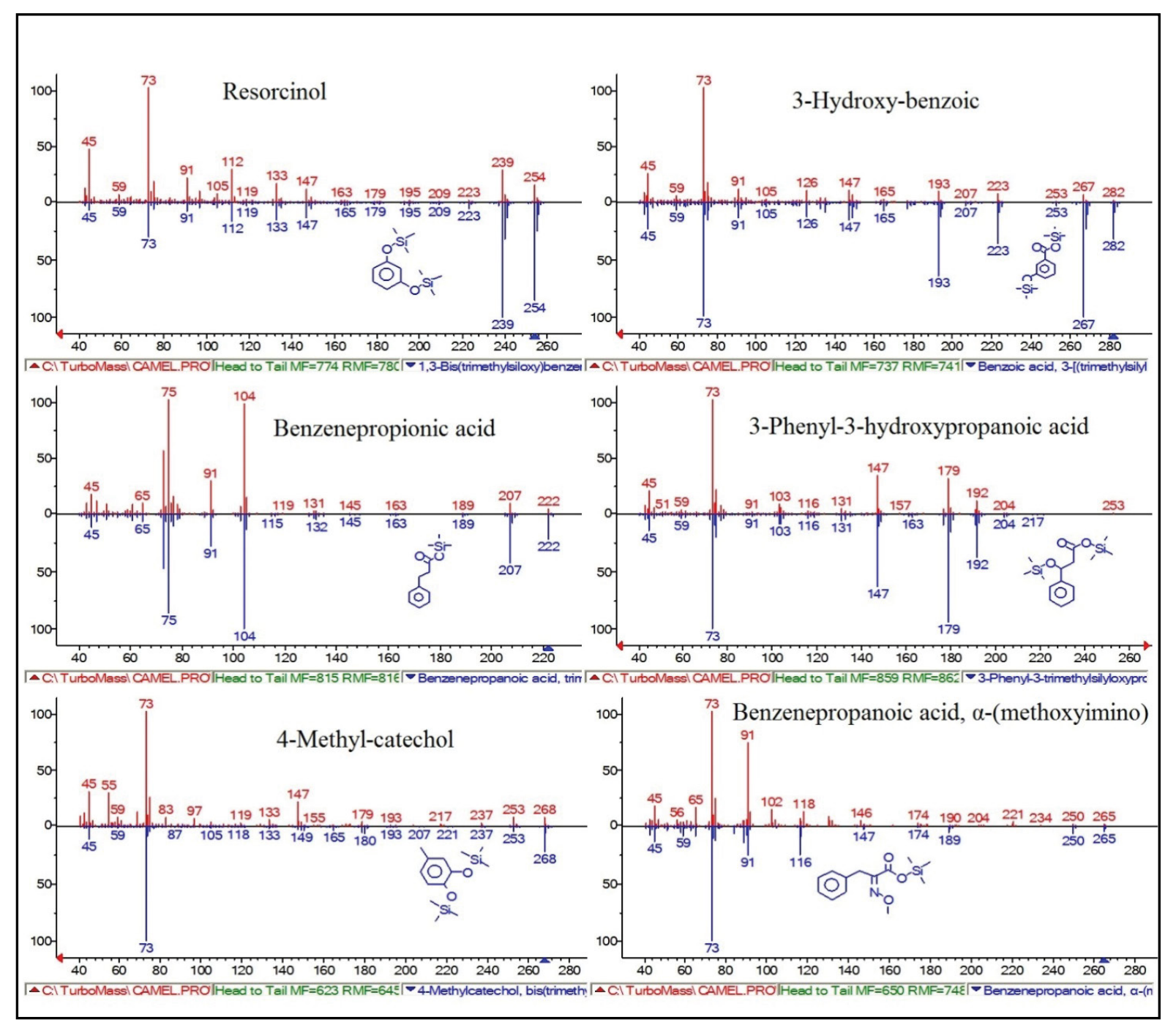

Fig. 2: EI-MS spectra of minor acidic and phenolic compounds.

EI-MS spectra of minor acidic and phenolic compounds found in the extract of enzymatic hydrolyzed CUR, as TMS derivative. 
of all determined compounds, was $100 \pm 0.8 \%$, using spiked water solution. The determined compounds include phenol (PHE), p-cresol (CRE), benzoic acid (BEN), salicylic acid (SAL), cinnamic acid (CIN) and azelaic acid (AZE) using 3-OH-MP as internal standard. The Sep-Pak ${ }^{\circledR}$ C8 column, $100 \mathrm{mg}$, showed a good results (100\% recovery) on loading 100-200 $\mu 1$ sample volume. After washing the SPE column, nitrogen gas was purged forcedly throughout the column to expel the residual amount of adsorbed water, because MSTFA was rapidly deactivated in moisture containing solvent. The eluted extract was mixed with $100 \mu 10.6 \%$ triethylamine (in acetone) to ovoid the loss of volatile phenolic compounds during the process of drying. These precautions showed a precise extraction recovery value, reached to $100 \pm 0.8 \%$. The hydrolyzed CUR samples were immediately extracted, or left inside the refrigerator (at $4^{\circ}$ ), because phenol and p-cresol were turned red if stand for $2 \mathrm{~h}$ (day light). The SPE C8 and $\mathrm{C} 18$ columns showed the same recovery results. However, more volume of the extraction solvent $(4 \mathrm{ml})$ was required in case of using $\mathrm{C} 18 / 1 \mathrm{ml}$ columns. The calibration parameters of the determined compounds are listed in Table 1.

The regression coefficient was close to unity, for all compounds, as shown in Table 1. The average EI-MS scan, of each peak at definite retention times, was defined to the Turbo Mass software to integrate the GCMS peaks selectively. This method showed an inter-day and intraday precision values of not more than 1.62 and $0.81 \%$ (relative standard deviation, RSD), respectively.
The percentage error of spiked sample, over three levels, includes 75,100 and $125 \%$ of claimed content, were not more than $0.07 \%$. The method deemed to be accurate, precise and selective.

The free and conjugated major acidic compounds were determined in CUR and matched with the measured concentrations in urine of healthy human, $\mathrm{n}=6$. The quantitation data showed that the average concentrations of p-cresol and azelaic acid in camel urine were 107 and $69 \mathrm{mg} / 100 \mathrm{ml}$, respectively (Table 2 ). The total concentration of benzoic acid (free and conjugated) in CUR were about $410 \mathrm{mg} / 100 \mathrm{ml}$, while, the concentration of the free (unconjugated) form was $40.0 \mathrm{mg} / 100 \mathrm{ml}$ (fig. 3). The reported amount of benzoic acid in non-hydrolyzed CUR was $1484 \mu \mathrm{mol} /$ mmol creatinine (equivalent to $18 \mathrm{mg} / 100 \mathrm{ml})^{[2]}$. This variation could be due to the geographical location of used camels. Moreover, the measured total amount of benzoic acid was equal to ten folds as free form. This clarify that benzoic acid is existed majorly in form of hippuric acid, i.e. glycine conjugate. These results confirmed that benzoic acid, phenol, p-cresol and cinnamic acid are existed majorly in conjugated form. The concentrations of targeted compounds were very low in human urine, relative to the camel urine (Table 2). Azelaic acid was not detected in human urine.

The estimated compounds were prepared in water and mixed with an equimolar amount of $\mathrm{KOH}$ (Table 2). This solution mixture prepared to contain the same corresponding total concentrations in camel urine

TABLE 1: CALIBRATION PARAMETERS, LOD AND LOQ OF ASSAYED COMPOUNDS

\begin{tabular}{lcccccc}
\hline Name & Slope & Intercept & $r^{*}$ & LOD, g/ml & LOQ, $\mu g / m l$ & Range, $\mu \mathrm{g} / \mathrm{ml}$ \\
\hline Phenol & 0.00689937 & -0.05158 & 0.9991 & 0.05 & 0.10 & $2.0-500$ \\
p-cresol & 0.00571764 & -0.01628 & 0.9981 & 0.04 & 0.10 & $2.0-500$ \\
Benzoic acid & 0.0057987 & 0.01096 & 0.9995 & 0.05 & 0.20 & $4.0-500$ \\
Salicylic acid & 0.00145584 & -0.01006 & 0.9987 & 0.05 & 0.20 & $4.0-500$ \\
Cinnamic acid & 0.00243503 & -0.02321 & 0.9985 & 0.05 & 0.20 & $4.0-500$ \\
Azelaic acid & 0.00371740 & 0.00596 & 0.9981 & 0.05 & 0.20 & $4.0-500$ \\
\hline
\end{tabular}

${ }^{*}$, regression coefficient; $n=6$

TABLE 2: CONCENTRATION OF TARGETED COMPONENTS IN FRESHAND ENZYMATICALLY HYDROLYZED, CAMEL URINE AND HUMAN URINE

\begin{tabular}{lcccc}
\hline \multirow{2}{*}{ Substance } & \multicolumn{2}{c}{ Camel urine } & \multicolumn{2}{c}{ Human urine } \\
\cline { 2 - 5 } & Free & Total & Free & Total \\
\hline Phenol & $0.2(8.8)$ & $4.0(7.5)$ & 0.0 & $0.14(8.1)$ \\
p-cresol & $33.8(5.1)$ & $107.2(8.9)$ & $0.2(7.9)$ & $2.84(15.8)$ \\
Benzoic acid & $40.0(3.7)$ & $490.6(12.5)$ & 0.0 & $0.37(11.2)$ \\
Salicylic acid & $4.5(1.2)$ & $42.7(2.2)$ & 0.0 & $0.18(1.9)$ \\
Cinnamic acid & $0.3(6.6)$ & $3.2(4.5)$ & 0.0 & $0.23(0.7)$ \\
Azelaic acid & $55.9(4.4)$ & $68.6(6.7)$ & 0.0 & 0.0 \\
\hline
\end{tabular}

Values are reported as mg/100 ml (RSD); @n=24; @@n=6 
www.ijpsonline.com

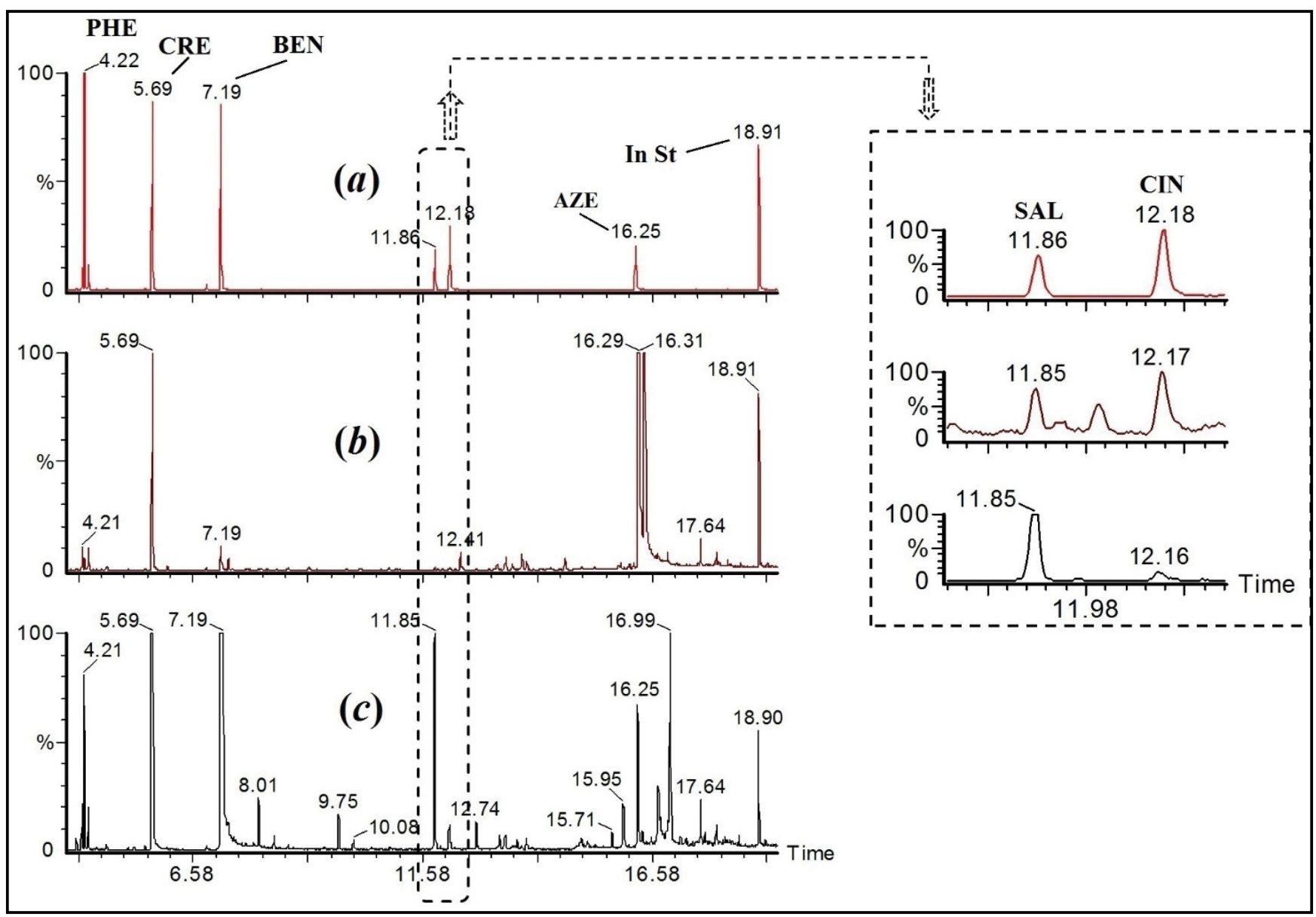

Fig. 3: GC-MS chromatograms.

GC-MS chromatograms of standard mix (a), hydrolyzed human urine extract (b) and (c) hydrolyzed camel urine extract.

TABLE 3: THE ANTIMICROBIAL AND ANTIFUNGAL TEST RESULTS OF INVESTIGATED SAMPLES

\begin{tabular}{ccccccc}
\hline Sample & \multicolumn{7}{c}{ Inhibition zone diameter (mm/mg sample) } \\
\cline { 2 - 7 } & B. subtilis & E. coli & P. aeruginosa & S. aureus & $\begin{array}{c}\text { A. flavus } \\
\text { (fungus) }\end{array}$ & $\begin{array}{c}\text { C. albicans } \\
\text { (fungus) }\end{array}$ \\
\hline Control: DMSO & 0 & 0 & 0 & 0 & 0 & 0 \\
Ampicillin & 20 & 22 & 17 & 18 & N/A & N/A \\
Amphotericin B & N/A & N/A & N/A & N/A & 17 & 19 \\
Camel urine (fresh) & 9 & 11 & 8 & 12 & 13 & 12 \\
$\quad \begin{array}{c}\text { Camel urine } \\
\text { hydrolyzed) }\end{array}$ & 15 & 20 & 16 & 17 & 18 & 20 \\
Simulated solution & 13 & 18 & 18 & 18 & 18 & 20 \\
\hline
\end{tabular}

samples. The prepared solution showed approximately the same results showed by the enzymatically hydrolyzed CUR sample. However, the fresh CUR sample showed, relatively, less antimicrobial and antifungal activities. In Table 3 it is shown that, the prepared standard solution mixture and CUR (hydrolyzed) are effective against Bacillus subtilis, E. coli, $P$. aeruginosa, $S$. aureus, $A$. flavus (fungus) and $C$. albicans (fungus).

In conclusion, a relatively, high concentrations of bioactive materials were found in camel urine, including; phenol, p-cresol, cinnamic acid, salicylic acid and azelaic acid. These compounds, separately reported to exhibit antiseptic, antiinflammatory, antiacne, antiscabies and anticancer effects. The high concentration of $\mathrm{p}$-cresol and azelaic acid, relative to known doses, confirm the antibacterial activities. These compounds execrated majorly as glucuronide conjugate. Moreover, the adapted extraction and analysis procedure were suitable for detection and 
quantification of phenolic and acidic bioactive constituents in camel urine.

\section{Acknowledgements:}

The Deanship of Scientific Research (DSR), King Abdulaziz University, Jeddah (grant no. 1434/166/125) funded this study. The author therefore acknowledges and thanks the DSR for technical and financial support.

\section{Financial support and sponsorship:}

The financial support from the Deanship of Scientific Research (DSR) is gratefully acknowledged.

\section{Conflicts of interest:}

The author declares no competing interests.

\section{REFERENCES}

1. Read BE. Chemical constituents of camel's urine. J Biol Chem 1925;64:615-7.
2. Antakly T. Bioactive compounds in camel urine and milk. WO Patents 2012;WO2012019295A1.

3. Al-Abdalall AHA. The inhibitory effect of camel's urine on mycotoxins and fungal growth. Afr J Agric Res 2010;5:1331-7.

4. Alhaidar A, Abdel Gader AG, Mousa SA. The antiplatelet activity of camel urine. J Altern Complement Med 2011;17:803-8.

5. Neugebauer M, Khedr A, el-Rabbat N, el-Kommos M, Saleh G. Stereoselective metabolic study of famprofazone. Biomed Chromatogr 1997;11:356-61.

6. Bauer AW, Kirby WM, Sherris JC, Turck M. Antibiotic susceptibility testing by a standardized single disk method. Am J Clin Pathol 1966;45:493-6.

7. Yagil R, Berlyne GM. Sodium and potassium metabolism in the dehydrated and rehydrated bedouin camel. J Appl Physiol 1976;41:457-61.

8. Taplin D, Meinking TL. Scabies, lice and fungal infections. Prim Care 1989;16:551-76.

9. Woolery-Lloyd HC, Keri J, Doig S. Retinoids and azelaic acid to treat acne and hyperpigmentation in skin of color. J Drugs Dermatol 2013;12:434-7. 